Supporting Information

\title{
Efficient and Stable Evolution of Oxygen Using Pulse- Electrodeposited Ir/Ni Oxide Catalyst in Fe-Spiked KOH \\ Electrolyte
}

Luo Gong, Dan Ren, Yilin Deng and Boon Siang Yeo*

Department of Chemistry, National University of Singapore, 3 Science Drive 3, Singapore 117543

*Author to whom correspondence should be addressed: chmyeos@nus.edu.sg, Fax: +65 6779 1691, Tel: +65 65162836 


\section{S1. Optimization of deposition parameters}

Various quantities of $\mathrm{IrCl}_{3} \cdot \mathrm{xH}_{2} \mathrm{O}$ and $\mathrm{NiSO}_{4} \cdot 6 \mathrm{H}_{2} \mathrm{O}$ were respectively dissolved in $30 \mathrm{~mL}$ ultrapure water $(18.2 \mathrm{M} \Omega \cdot \mathrm{cm}$, Barnstead) to give deposition electrolytes $\mathrm{A}, \mathrm{B}, \mathrm{C}, \mathrm{D}$ and $\mathrm{E}$ (Table S1). $0.1 \mathrm{M} \mathrm{KCl} \mathrm{(BioXtra,} \geq 99.0 \%$, Sigma Aldrich) was added to improve the conductivity of the solutions.

Table S1. The weight of each chemical added to the deposition electrolyte (30mL)

\begin{tabular}{cccccccc}
\hline $\begin{array}{c}\text { Deposition } \\
\text { electrolyte }\end{array}$ & Pure Ir & A & B & C & D & E & Pure Ni \\
\hline $\begin{array}{c}\mathrm{IrCl}_{3} \cdot \mathrm{xH}_{2} \mathrm{O} \\
(\mathrm{mg})\end{array}$ & 8.96 & 7.17 & 5.37 & 4.48 & 3.58 & 1.79 & 0 \\
$\begin{array}{c}\mathrm{NiSO}_{4} \cdot 6 \mathrm{H}_{2} \mathrm{O} \\
(\mathrm{mg})\end{array}$ & 0 & 1.58 & 3.15 & 3.94 & 4.73 & 6.31 & 7.89 \\
$\mathrm{KCl}(\mathrm{mg})$ & 223.65 & 223.65 & 223.65 & 223.65 & 223.65 & 223.65 & 223.65 \\
\hline
\end{tabular}

Cyclic voltammetry cycles (between $-1.59 \mathrm{~V}$ and $2.41 \mathrm{~V}$ vs RHE; all potentials subsequently reported in this work are with respect to the RHE) were first conducted at 100 $\mathrm{mV} / \mathrm{s}$ in the representative Electrolyte $\mathrm{C}$ to determine the possible deposition potentials. A mechanically-polished glassy carbon disc was used as the working electrode. The $3^{\text {rd }} \mathrm{CV}$ scan is shown in Figure $\mathrm{S} 1$.

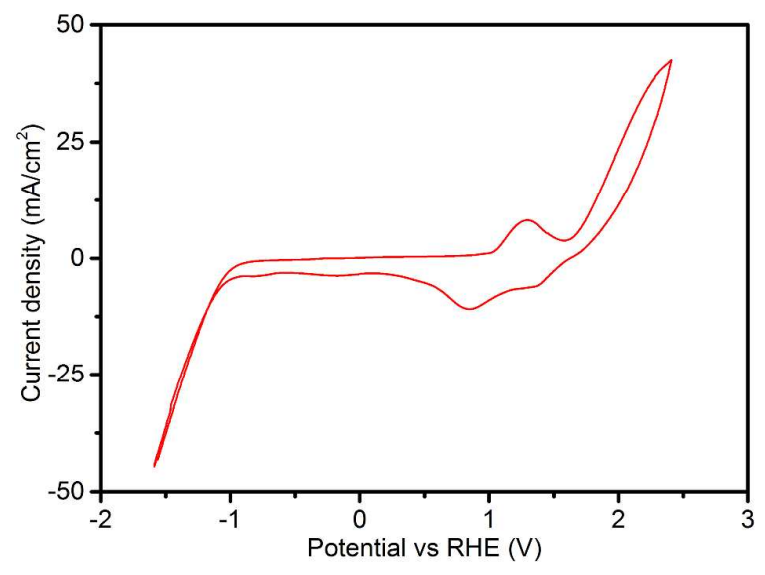

Figure S1. Cyclic voltammetry in Electrolyte $\mathrm{C}$ to determine the deposition potentials.

The Ir/Ni oxide was then deposited onto the glassy carbon electrode under different positive (from $1.21 \mathrm{~V}$ to $2.91 \mathrm{~V}$ ) and negative (from $-0.39 \mathrm{~V}$ to $-2.09 \mathrm{~V}$ ) potential combinations for $10 \mathrm{~min}$. LSV scans of the deposited films were subsequently conducted in 1 $\mathrm{M} \mathrm{KOH}$ at $10 \mathrm{mV} / \mathrm{s}$ from $0.93-1.68 \mathrm{~V}$ to assess their OER activities. The OER current 
density at $\eta=300 \mathrm{mV}$ was used to indicate the activity of the obtained catalyst. 74 different combinations were tested, and $2.01 \mathrm{~V}$ and $-1.29 \mathrm{~V}$ were respectively the best positive and negative potentials for optimized OER activities. The OER current at $\eta=300 \mathrm{mV}$ increased from an insignificant level $\left(\sim 0.4 \mathrm{~mA} / \mathrm{cm}^{2}\right)$ to $21.1 \pm 2.6 \mathrm{~mA} / \mathrm{cm}^{2}$ under the optimized condition. These optimized parameters were also used for depositing the other four mixed metal oxides (A, B, D and E).

The deposition of $\mathrm{IrO}_{\mathrm{x}}$ and $\mathrm{NiO}_{\mathrm{x}}$ was similarly optimized. 3.89 V_-3.11 V (among 62 combinations) and $1.31 \mathrm{~V}_{-}-0.89 \mathrm{~V}$ (among 60 combinations) were respectively the best conditions for depositing $\mathrm{IrO}_{x}$ and $\mathrm{NiO}_{x}$. The OER current densities of $\mathrm{IrO}_{x}$ at $\eta=300 \mathrm{mV}$ increased from $\sim 0.1$ to $48.0 \pm 8.6 \mathrm{~mA} / \mathrm{cm}^{2}$ and the OER current densities of $\mathrm{NiO}_{\mathrm{x}}$ at $\eta=450$ $\mathrm{mV}$ increased from $\sim 0.5$ to $3.36 \pm 0.23 \mathrm{~mA} / \mathrm{cm}^{2}$. 


\section{S2. Characterization of the catalysts}

\section{S2.1 Energy dispersive X-ray spectroscopy}

Each type of catalyst was measured twice using different samples. For each sample, five different areas were analysed (Figure S2a). A typical EDS spectrum of the $\mathrm{Ir} / \mathrm{Ni}$ oxide catalyst ( $\mathrm{Ir}: \mathrm{Ni}=1: 1.49)$ is shown in Figure $\mathrm{S} 2 \mathrm{~b}$. The $\mathrm{C}$ signal originates from either the GC substrate or spurious atmospheric contaminants, and the $\mathrm{Cl}$ signal is due to the $\mathrm{KCl}$ in the deposition solution. The average EDS results are summarized in Table S2.

(a)

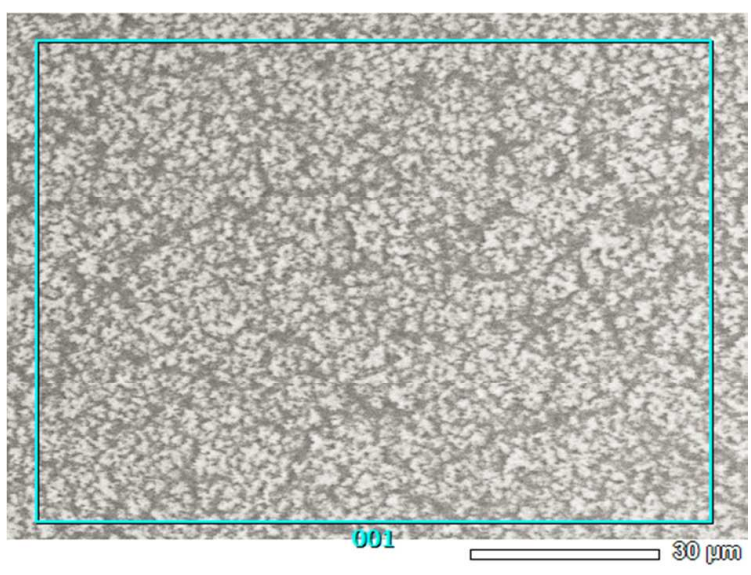

(b)

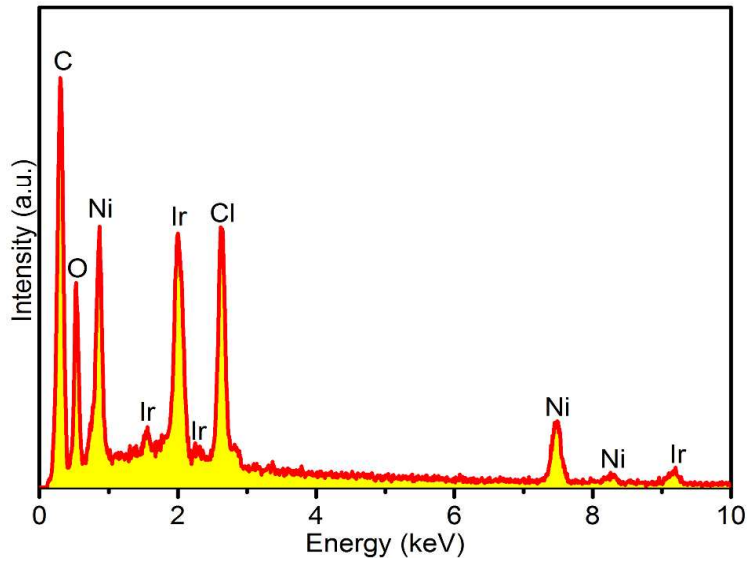

Figure S2. (a) An area chosen for EDS measurement (within the cyan rectangle). (b) A typical EDS spectrum of the Ir/Ni oxide catalyst.

Table S2. EDS measurements of the catalysts deposited from different deposition electrolytes

\begin{tabular}{c|c}
\hline Deposition electrolyte & Actual Ir:Ni ratios by EDS \\
\hline A & $1 \pm 0.09: 0.21 \pm 0.09$ \\
B & $1 \pm 0.09: 0.76 \pm 0.09$ \\
C & $1 \pm 0.17: 1.49 \pm 0.17$ \\
D & $1 \pm 0.06: 2.63 \pm 0.06$ \\
E & $1 \pm 0.15: 4.20 \pm 0.15$ \\
\hline
\end{tabular}




\section{S2.2 Scanning electron microscopy}

As the conductivity of the electrodeposited catalysts was rather poor, a thin Pt overlayer was coated over the sample before SEM imaging. Two samples were tested for each catalyst.
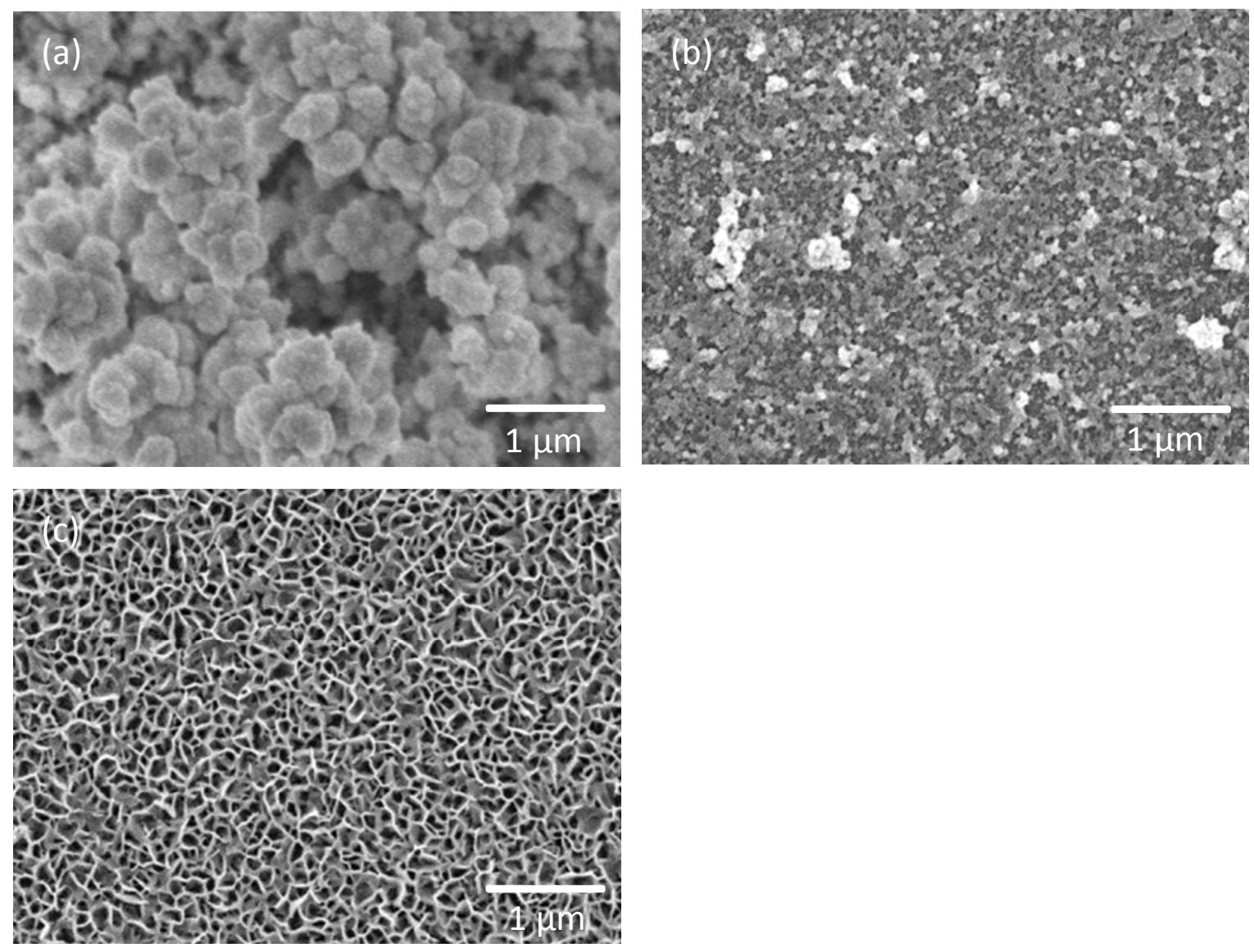

Figure S3. SEM images of (a) Ir/Ni oxide, (b) $\mathrm{IrO}_{\mathrm{x}}$ and (c) $\mathrm{NiO}_{\mathrm{x}}$. 


\section{S2.3 Transmission electron microscopy and selected area electron diffraction}

Samples were prepared by removing the electrodeposited catalysts from the glassy carbon working electrodes and dispersed them in ethanol. The suspension was then drop-casted onto Ni TEM grids, and allowed to dry, before TEM analysis.
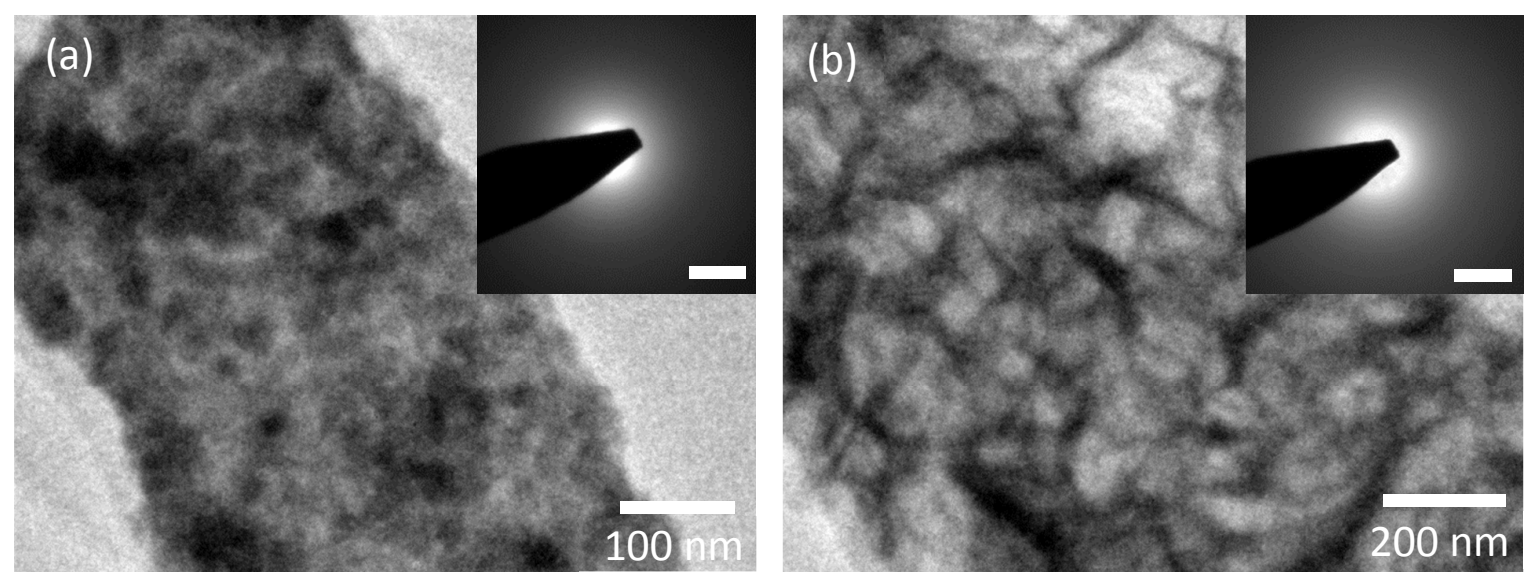

Figure S4. TEM images of (a) $\mathrm{IrO}_{\mathrm{x}}$ and (b) $\mathrm{NiO}_{\mathrm{x}}$. The insert in each figure is the SAED pattern of the respective catalysts. Scale bar of SAED pattern $=2 \mathrm{~nm}^{-1}$. 


\section{S2.4 X-ray diffraction}

X-ray diffraction of the optimized $\mathrm{Ir} / \mathrm{Ni}$ oxide catalyst was conducted with a rate of $0.02 \%$ step and an integration time of 2 s/step from 10-110 (20) (Figure S5). Only the characteristic peaks of the underlying glassy carbon substrate were observed.

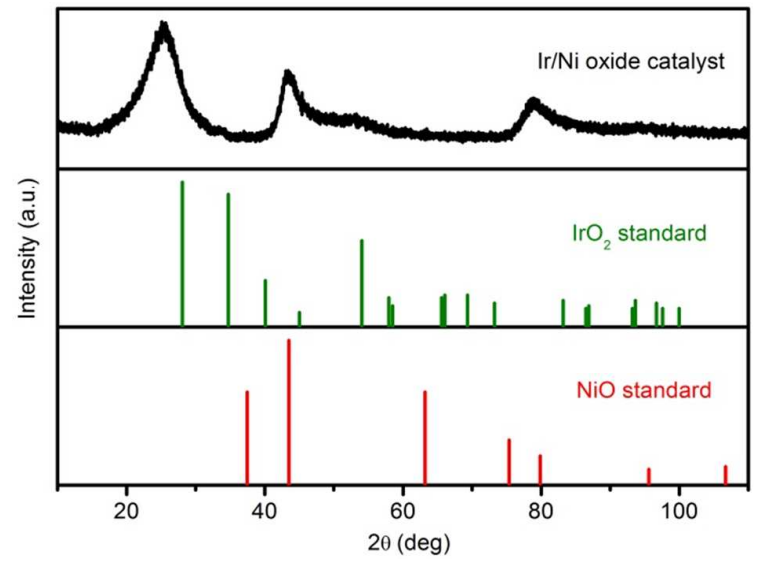

Figure S5. XRD pattern of the Ir/Ni oxide catalyst. The standard XRD pattern of $\mathrm{IrO}_{2}(\mathrm{PDF}$ 00-015-0870) and $\mathrm{NiO}$ (PDF 00-001-1239) were also included for comparison. 


\section{S2.5 Raman spectroscopy}

Shell-isolated nanoparticle-enhanced Raman spectroscopy (SHINERS) was used to enhance the intensity of Raman signals of all samples. The preparation of the $55 \mathrm{~nm}$ $\mathrm{Au} @ \mathrm{SiO}_{2}$ SHINs was adopted from a previously published protocol. ${ }^{1}$ TEM images of the synthesized SHINs were obtained to confirm its quality (Figure S6a). The Raman spectra of the catalysts are shown in Figure S6b.

(a)

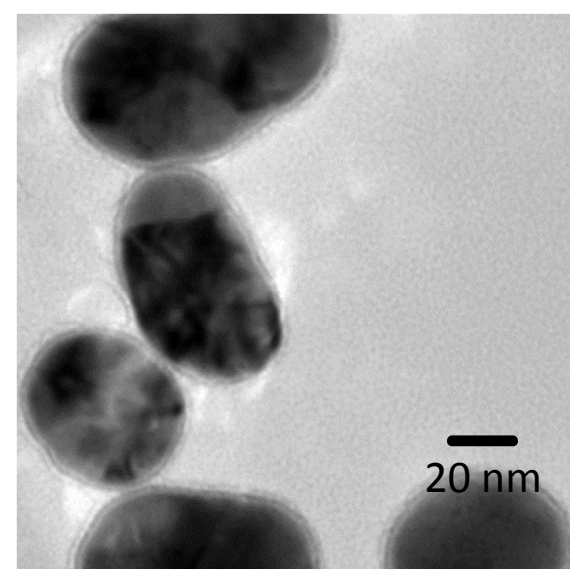

(b)

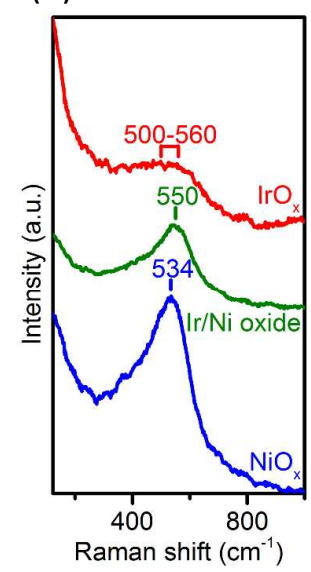

Figure S6. (a) TEM image of synthesized $55 \mathrm{~nm} \mathrm{Au@SiO} 2$ SHINs. (b) Raman spectrum of electrodeposited $\mathrm{IrO}_{\mathrm{x}}, \mathrm{Ir} / \mathrm{Ni}$ oxide and $\mathrm{NiO}_{\mathrm{x}}$. 


\section{S3. Electrochemical data}

\section{S3.1 Optimization of $\mathrm{Fe}^{3+}$ concentration}

Various concentrations of $\mathrm{Fe}^{3+}$ were spiked into the $1 \mathrm{M} \mathrm{KOH}$ electrolyte. Chronoamperometry (CA) of the $\mathrm{Ir} / \mathrm{Ni}$ oxide catalyst was then conducted at $\eta=300 \mathrm{mV}$ in those electrolytes. Their current densities after $1 \mathrm{~h} \mathrm{CA}$ were used as a gauge of the effect of added iron ions. The addition of $0.3 \mathrm{mM}$ iron ions into $1 \mathrm{M} \mathrm{KOH}$ gave the best result (Figure S7).

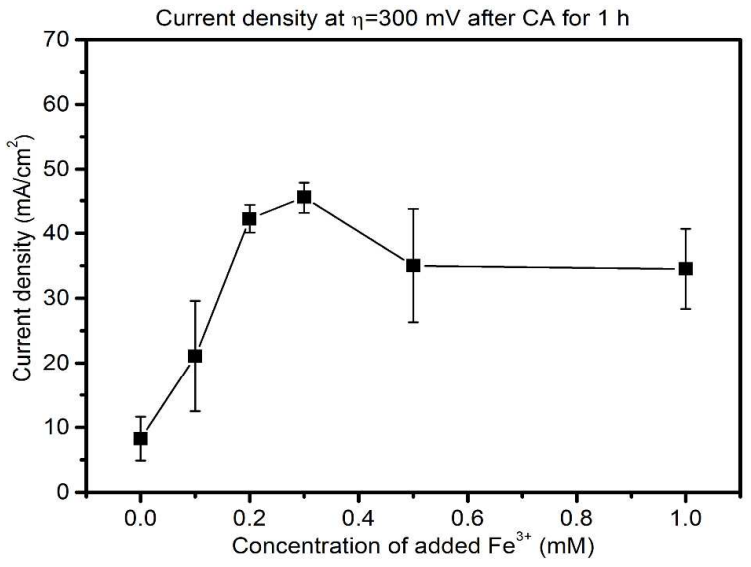

Figure S7. The optimization of the concentration of $\mathrm{Fe}^{3+}$ in the $1 \mathrm{M} \mathrm{KOH}$ electrolyte. 


\section{S3.2 Tafel slope}

The linear sweep voltammograms of the catalysts were measured at $1 \mathrm{mV} / \mathrm{s}$ in $1 \mathrm{M} \mathrm{KOH}$, and their Tafel plots are presented in Figure S8.

(a)

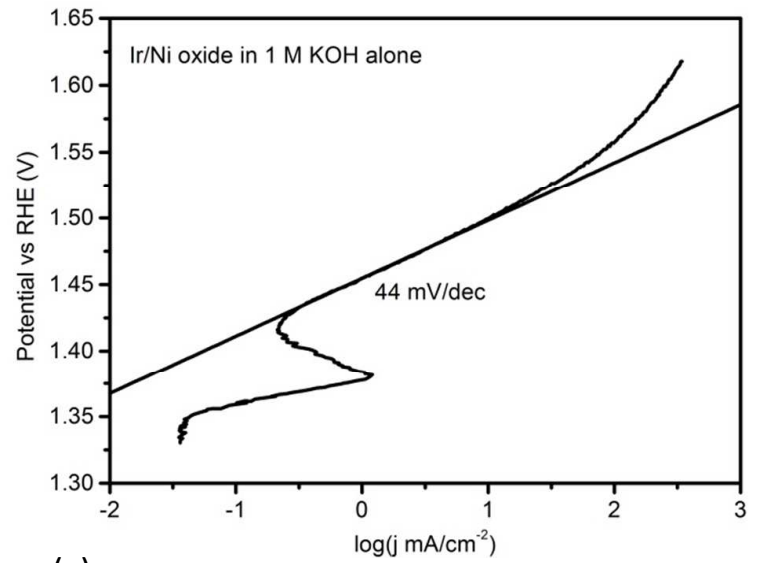

(b)

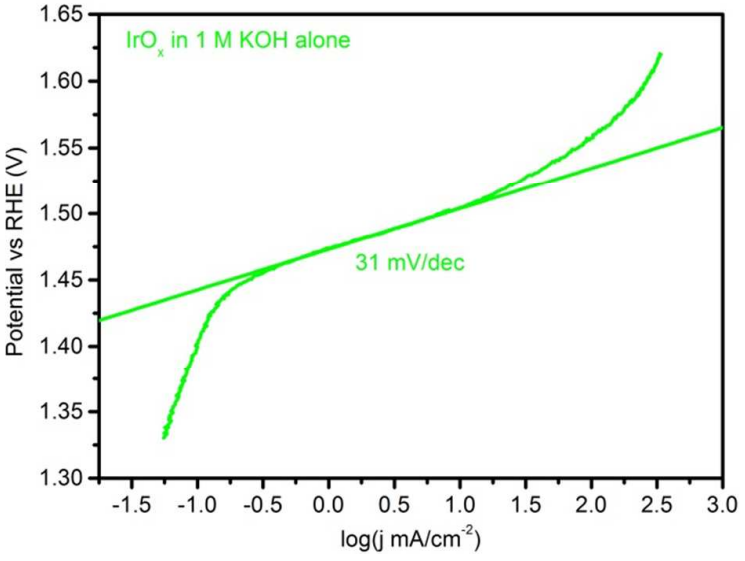

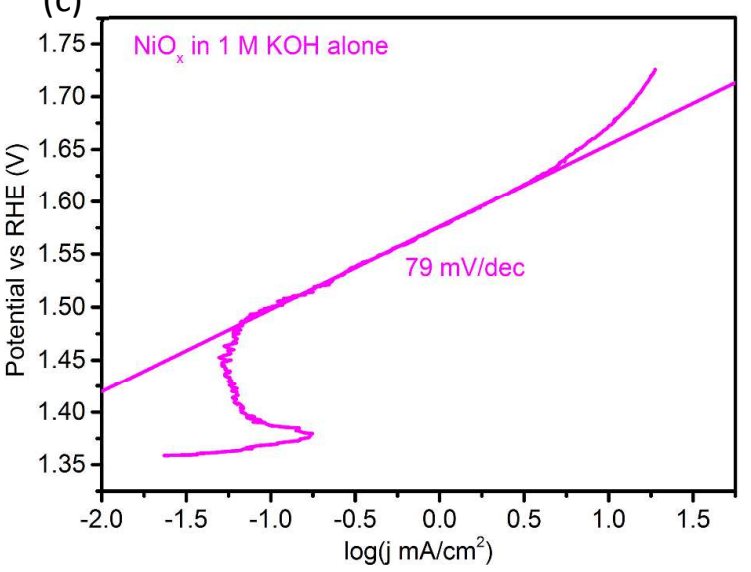

Figure S8. Tafel plots of (a) $\mathrm{Ir} / \mathrm{Ni}$ oxide catalyst, (b) $\mathrm{IrO}_{\mathrm{x}}$ and (c) $\mathrm{NiO}_{\mathrm{x}}$ measured at $1 \mathrm{mV} / \mathrm{s}$ in $1 \mathrm{M} \mathrm{KOH}$ electrolyte. 


\section{S3.3 Inductively coupled plasma atomic emission spectroscopy measurements and calculation of Ir mass based current}

To estimate the mass loading of catalyst on the electrode, ICP-AES measurements were conducted. Samples were prepared by dissolving the metal oxides from several electrodes into $1 \mathrm{M} \mathrm{HNO}_{3}$ solution by applying a potential of $1.73 \mathrm{~V}$ (vs RHE) for $30 \mathrm{~min}$. The nearzero current at the end of $30 \mathrm{~min}$ indicates the complete dissolution of the deposited catalyst in the $1 \mathrm{M} \mathrm{HNO}_{3}$ (Figure S9). In total, three sets (using several similarly-prepared electrodes for each set of measurements) of ICP tests were conducted for the $\mathrm{Ir} / \mathrm{Ni}$ oxide catalyst. The average metal amount ( $\mathrm{Ir}+\mathrm{Ni}$ ) for one electrode is $2.2 \pm 0.1 \mu \mathrm{g}$ ( or $30.7 \pm 1.7 \mu \mathrm{g} / \mathrm{cm}^{2}$ ).

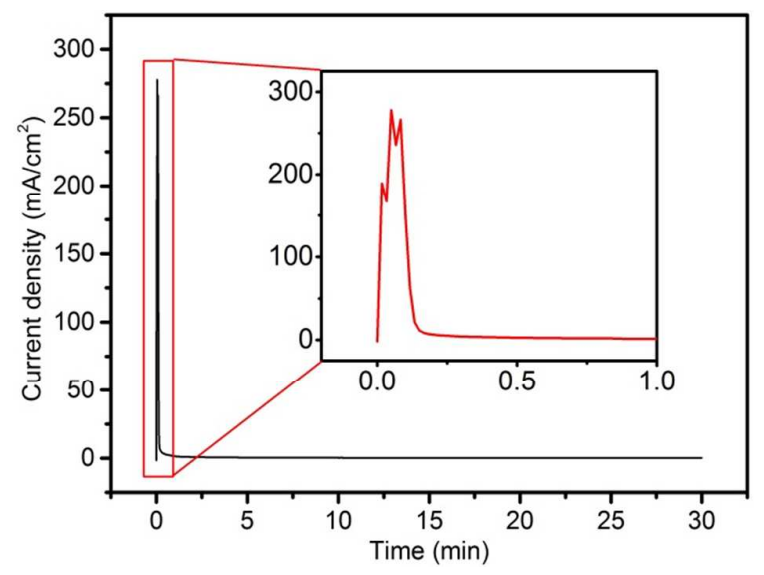

Figure S9. Chronoamperogram of dissolving $\mathrm{Ir} / \mathrm{Ni}$ oxide catalyst in $1 \mathrm{M} \mathrm{HNO}_{3}$. The inset is the zoom in of the curve within the red rectangle area.

From ICP-AES, $\mathrm{m}_{\mathrm{Ir}}=1.5 \mu \mathrm{g}$ for one electrode.

To calculate the Ir mass based current in $1 \mathrm{M} \mathrm{KOH}$ :

If $\eta=250 \mathrm{mV}, \mathrm{I}_{\text {average }}=0.38 \mathrm{~mA}$,

$$
\frac{0.38}{1.5 \times 10^{-3}} \approx 253 m A / m g
$$

If $\eta=280 \mathrm{mV}, \mathrm{I}_{\text {average }}=1.41 \mathrm{~mA}$,

$$
\frac{1.41}{1.5 \times 10^{-3}} \approx 940 \mathrm{~mA} / \mathrm{mg}
$$

In $1 \mathrm{M} \mathrm{KOH}+0.3 \mathrm{mM} \mathrm{Fe}^{3+}$, at $\eta=250 \mathrm{mV}, \mathrm{I}_{\text {average }}=0.44 \mathrm{~mA}$, thus

$$
\frac{0.44}{1.5 \times 10^{-3}} \approx 293 \mathrm{~mA} / \mathrm{mg}
$$

If $\eta=280 \mathrm{mV}, \mathrm{I}_{\text {average }}=1.89 \mathrm{~mA}$, thus

$$
\frac{1.89}{1.5 \times 10^{-3}} \approx 1260 \mathrm{~mA} / \mathrm{mg}
$$




\section{S4. Stability}

\section{S4.1 Electrochemically active surface area (ECSA) of the Ir/Ni oxide}

The ECSA of the Ir/Ni oxide catalyst was estimated using its double layer capacitance $\left(\mathrm{C}_{\mathrm{dl}}\right) .^{2-3} \mathrm{~A}$ non-faradaic potential range of $0.83 \mathrm{~V}$ to $1.03 \mathrm{~V}$ vs RHE was chosen to conduct cyclic voltammetry with scan rates of 100 to $800 \mathrm{mV} / \mathrm{s}$ (representative data presented in Figure S10(a)). The anodic and cathodic currents from each CV curve at $0.93 \mathrm{~V}$ were designated respectively as $i_{a}$ and $i_{c}$. $i_{a}$ and $i_{c}$ were then plotted against the scan rate, and the absolute value of the slope of the fitted line is the $\mathrm{C}_{\mathrm{dl}}$ (Figure $\mathrm{S} 10(\mathrm{~b})$ ). The double layer capacitance for each measurement was taken as the average of the anodic and the cathodic values.

(a)

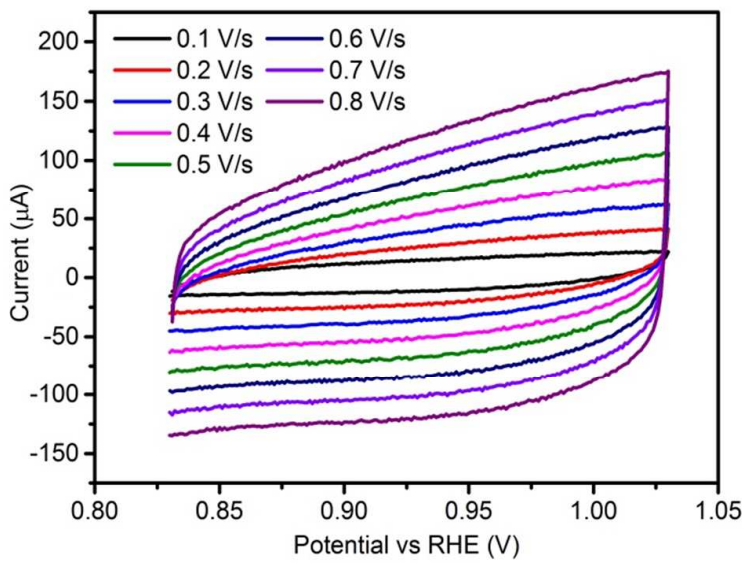

(b)

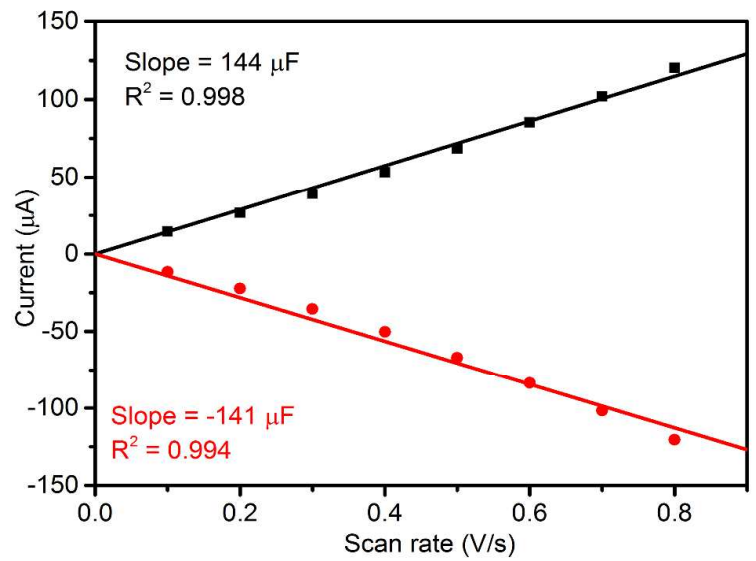

Figure S10. (a) Cyclic voltammograms of $\mathrm{Ir} / \mathrm{Ni}$ oxide catalyst in $1 \mathrm{M} \mathrm{KOH}+\left(\mathrm{Fe}^{3+}, \mathrm{Ni}^{2+}\right.$, $\mathrm{Ir}^{3+}$ ) at different scan rates. (b) $i_{\mathrm{a}}$ and $i_{\mathrm{c}}$ plotted against scan rate, respectively.

Using this method, the double layer capacitances of the $\mathrm{Ir} / \mathrm{Ni}$ oxide catalyst in pure $1 \mathrm{M}$ $\mathrm{KOH}$ and in $1 \mathrm{M} \mathrm{KOH}$ (spiked with $\mathrm{Fe}^{3+}, \mathrm{Ni}^{2+}, \mathrm{Ir}^{3+}$ ) were measured to be $145 \pm 19$ and $127 \pm 20$ $\mu \mathrm{F}$, respectively. By taking a general specific capacitance of $40 \mu \mathrm{F} / \mathrm{cm}^{2},{ }^{2-3}$ the corresponding ECSAs of these catalysts were calculated to be 3.6 and $3.2 \mathrm{~cm}^{2}$. The geometric surface area of the glassy carbon working electrode is $0.0707 \mathrm{~cm}^{2}$. The roughness factors are thus 51 and 45 respectively. 


\section{S4.2 Post-OER EDS}

EDS measurements of the $\mathrm{Ir} / \mathrm{Ni}$ oxide catalyst were conducted after it was subjected to chronopotentiometry at $10 \mathrm{~mA} / \mathrm{cm}^{2}$ under various conditions. The results are presented in Table S3. The reported $\operatorname{Ir}(\%)$ and $\mathrm{Ni}(\%)$ only indicate their relative percentage.

Table S3. Post-OER EDS measurements under different conditions

\begin{tabular}{c|c|c}
\hline Conditions & $\operatorname{Ir}(\%): \mathbf{N i}(\%)$ & Standard deviation(\%) $^{\mathbf{a}}$ \\
\hline As prepared Ir/Ni oxide & $40.14: 59.86$ & \pm 6.80 \\
CP in 1 M KOH, 1 h & $20.69: 79.31$ & \pm 2.11 \\
CP in 1 M KOH, 1.5 days & $16.82: 83.18$ & \pm 1.12 \\
CP in 1 M KOH+Ir ${ }^{3+}, \mathbf{3 . 5}$ days & $24.25: 75.75$ & \pm 2.55 \\
CP in 1 M KOH+Ni $\mathbf{~}^{2+}, \mathbf{2 . 5}$ days & $13.92: 86.08$ & \pm 4.25 \\
\hline
\end{tabular}

a. Standard deviation applies to both $\operatorname{Ir}(\%)$ and $\mathrm{Ni}(\%)$.

CP: chronopotentiometry.

During EDS measurements, we only chose Ir and Ni atoms to do the quantification. Thus $\mathrm{Ir} \%+\mathrm{Ni} \%=100 \%$ always holds. 


\section{S4.3 The effect of $\mathrm{Cl}^{-}$ions}

Chlorine evolution reaction (CER) is a competitive reaction to OER. ${ }^{4}$ To evaluate the influence of $\mathrm{Cl}^{-}$ions in our experiment, we conducted chronopotentiometry tests of $\mathrm{Ir} / \mathrm{Ni}$ oxide catalyst at $10 \mathrm{~mA} / \mathrm{cm}^{2}$ in $1 \mathrm{M} \mathrm{KOH}$ (with $0.3 \mathrm{mM} \mathrm{Fe}^{3+}$ and $0.3 \mathrm{mM} \mathrm{Ni}^{2+}$ added), both with and without added $\mathrm{Cl}^{-}(0.9 \mathrm{mM})$. The addition of $\mathrm{Cl}^{-}$to the electrolyte did not have an apparent effect on the stability of the Ir/Ni oxide catalyst (Figure S11). The trends of the catalyst degradation were the same with or without added $\mathrm{Cl}^{-}$ions. The overpotential required to achieve $10 \mathrm{~mA} / \mathrm{cm}^{2}$ current density was also not lowered.

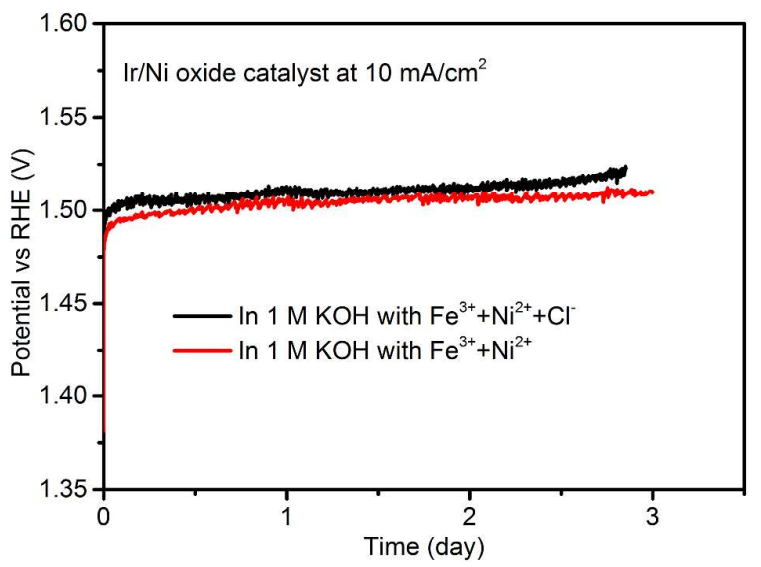

Figure S11. Chronopotentiometry curves of Ir/Ni oxide catalyst at $10 \mathrm{~mA} / \mathrm{cm}^{2}$ in $1 \mathrm{M} \mathrm{KOH}$ $\left(\mathrm{Fe}^{3+}\right.$ and $\mathrm{Ni}^{2+}$ added), both with and without $\mathrm{Cl}^{-}$.

In the chronopotentiometry test of $\mathrm{Ir} / \mathrm{Ni}$ oxide catalyst in $1 \mathrm{M} \mathrm{KOH}$ with added $\mathrm{Fe}^{3+}, \mathrm{Ni}^{2+}$ and $\mathrm{Ir}^{3+}$, the concentration of $\mathrm{Cl}^{-}$added to the electrolyte was $\leq 0.384 \mathrm{mM}$ at the beginning $(30 \mathrm{~mL})$. When we changed half of the electrolyte every day, the concentration of $\mathrm{Cl}^{-}$in the newly added electrolyte $(15 \mathrm{~mL})$ was also $\leq 0.384 \mathrm{mM}$. During the one week's experiment, the maximal total amount of added $\mathrm{Cl}^{-}$was

$$
n\left[\mathrm{Cl}^{-}\right]=0.384 \times(30+15 \times 6)=46.08 \mu \mathrm{mol}
$$

Assume

$$
2 \mathrm{Cl}^{-} \rightarrow \mathrm{Cl}_{2}+2 e^{-}
$$

Thus

$$
Q_{C E R}=46.08 \times 10^{-6} \times 96485 \approx 4.446 C
$$

Total charge passed

$$
Q_{\text {total }}=I t=0.707 \times 10^{-3} \times 7 \times 24 \times 3600=427.5936 C
$$

Thus any possible contribution of CER to the total current

$$
\frac{Q_{\text {CER }}}{Q_{\text {total }}}=\frac{4.446}{427.5936}<1.04 \%
$$




\section{S4.4 Comparison of long term stability}

McCrory et al. tested the stability of many OER catalysts in $1 \mathrm{M} \mathrm{NaOH}$ at $10 \mathrm{~mA} / \mathrm{cm}^{2} .^{2-3}$ All their benchmarked catalysts were electrodeposited on glassy carbon disc electrodes $\left(0.196 \mathrm{~cm}^{2}\right)$. Table S4 were adapted from their works. The Ir/Ni oxide catalyst in $1 \mathrm{M} \mathrm{KOH}$ spiked with $\mathrm{Fe}^{3+}, \mathrm{Ni}^{2+}$ and $\mathrm{Ir}^{3+}$ shows better OER performance and long term stability than these benchmarked catalysts.

Table S4. Comparison of some OER catalysts' stability at $10 \mathrm{~mA} / \mathrm{cm}^{2}$

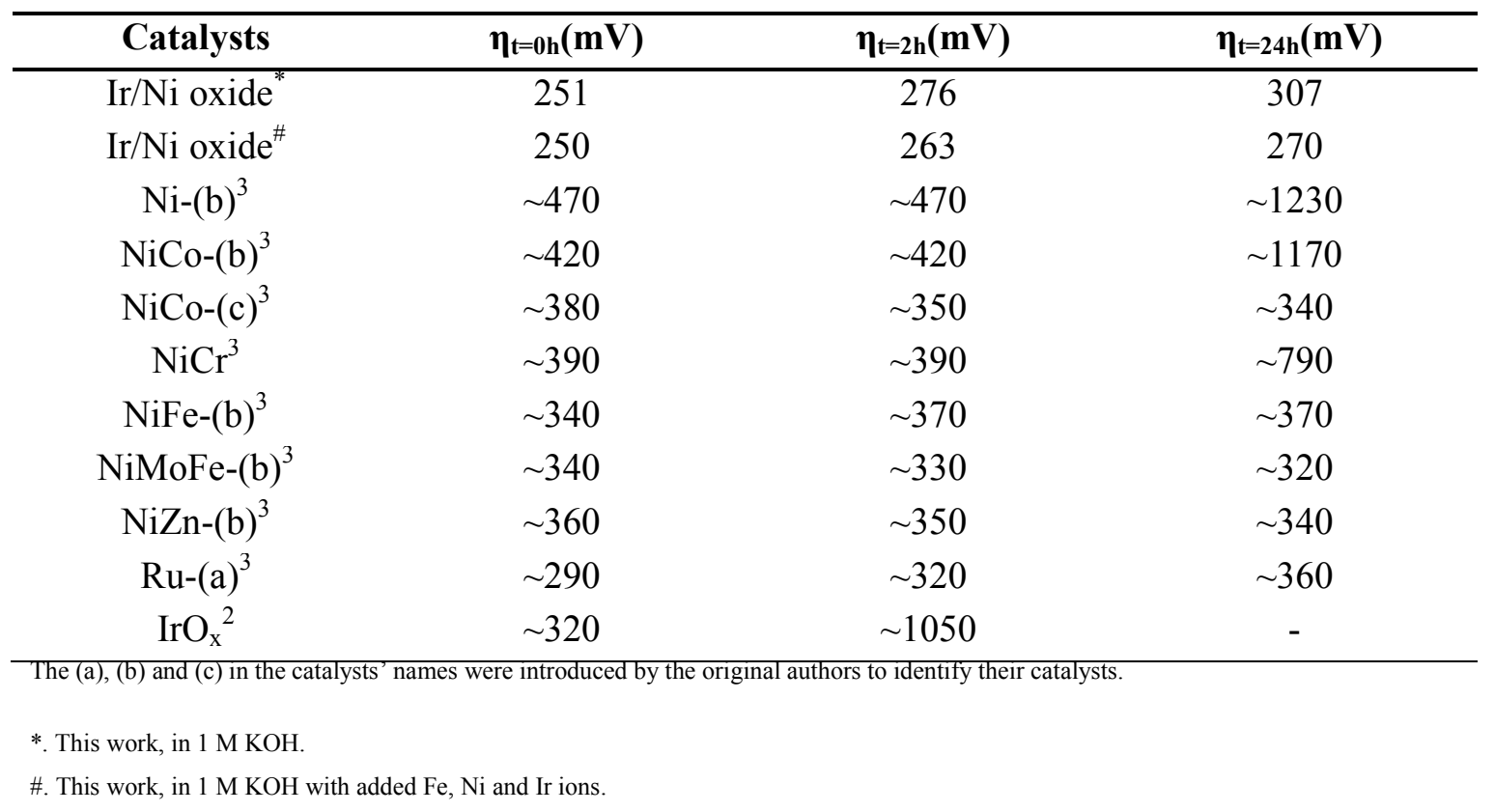


S4.5 EDS elemental mapping
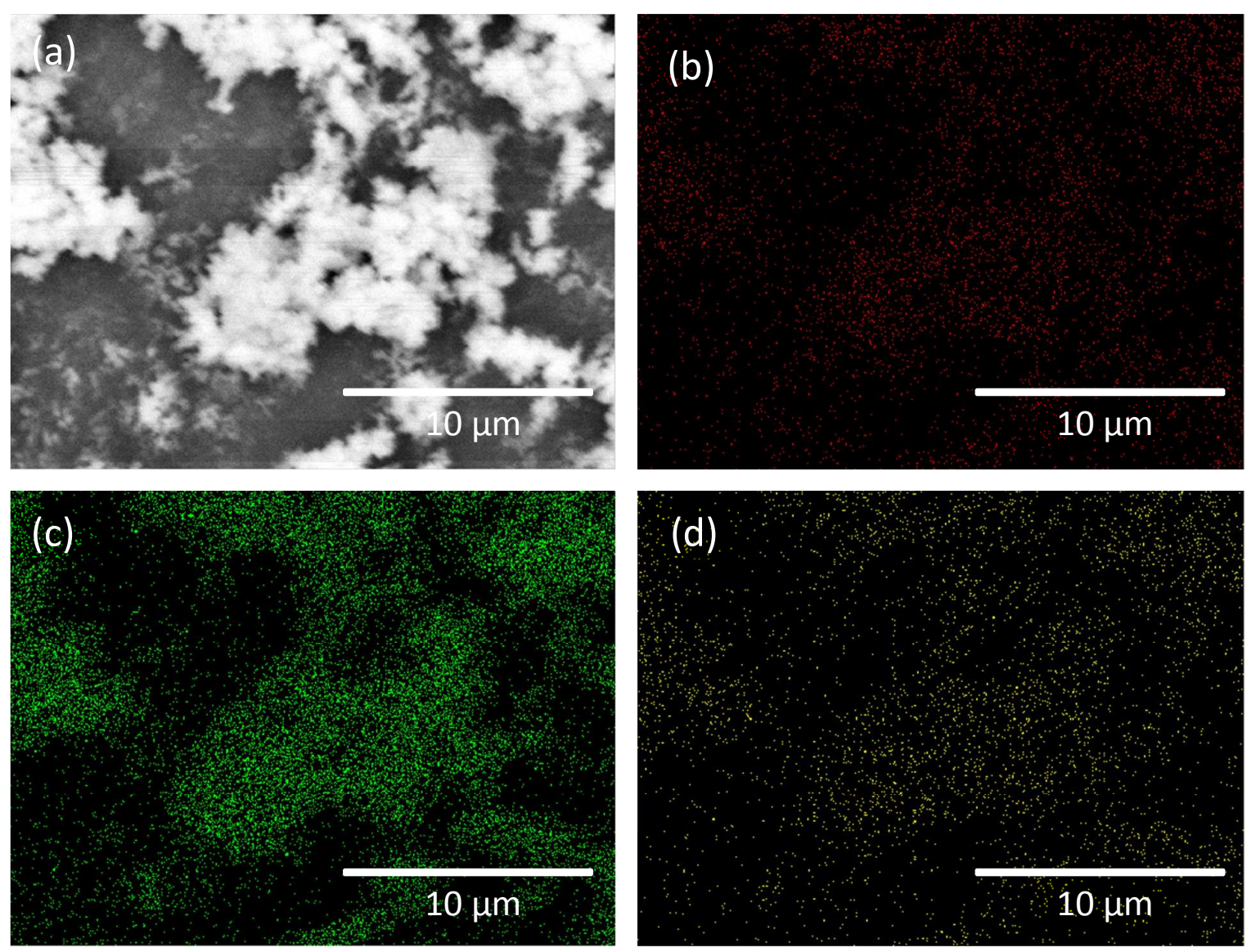

Figure S12. SEM and EDS elemental mapping of the $\mathrm{Ir} / \mathrm{Ni}$ oxide catalyst, which has undergone chronopotentiometry at $10 \mathrm{~mA} / \mathrm{cm}^{2}$ in $1 \mathrm{M} \mathrm{KOH}+0.3 \mathrm{mM} \mathrm{Fe} \mathrm{F}^{3+}$ for 2 hours. (a) SEM image of the selected area. The corresponding elemental mapping was shown for (b) $\mathrm{Fe}$, (c) Ni and (d) Ir. 


\section{References}

(1) Li, J. F.; Tian, X. D.; Li, S. B.; Anema, J. R.; Yang, Z. L.; Ding, Y.; Wu, Y. F.; Zeng, Y. M.; Chen, Q. Z.; Ren, B.; Wang, Z. L.; Tian, Z. Q. Surface Analysis Using ShellIsolated Nanoparticle-Enhanced Raman Spectroscopy. Nat. Protoc. 2013, 8, 52-65.

(2) McCrory, C. C. L.; Jung, S.; Peters, J. C.; Jaramillo, T. F. Benchmarking Heterogeneous Electrocatalysts for the Oxygen Evolution Reaction. J. Am. Chem. Soc. 2013, 135, 16977-16987.

(3) McCrory, C. C. L.; Jung, S.; Ferrer, I. M.; Chatman, S. M.; Peters, J. C.; Jaramillo, T. F. Benchmarking Hydrogen Evolving Reaction and Oxygen Evolving Reaction Electrocatalysts for Solar Water Splitting Devices. J. Am. Chem. Soc. 2015, 137, 4347-4357.

(4) Macounová, K.; Makarova, M.; Jirkovský, J.; Franc, J.; Krtil, P. Parallel Oxygen and Chlorine Evolution on $\mathrm{Ru}_{1-\mathrm{x}} \mathrm{Ni}_{\mathrm{x}} \mathrm{O}_{2-\mathrm{y}}$ Nanostructured Electrodes. Electrochim. Acta 2008, 53, 6126-6134. 